University of Nebraska - Lincoln

DigitalCommons@University of Nebraska - Lincoln

2008

\title{
A New Chilean Species of Cycloneda Crotch (Coleoptera: Coccinellidae: Coccinellinae: Coccinellini)
}

Natalia J. Vandenberg ystematic Entomology Lab (SEL), Plant Sciences Institute, Agricultural Research Service, USDA, c/o National Museum of Natural History, Smithsonian Institution, P.O. Box 37012, MRC-168, Washington, DC 20013-7012, Natalia.Vandenberg@ars.usda.gov

Guillermo González

Santiago, Chile, Nocedal 6455 La Reina, willogonzalez@yahoo.com

Follow this and additional works at: https://digitalcommons.unl.edu/systentomologyusda

Part of the Entomology Commons

Vandenberg, Natalia J. and González, Guillermo, "A New Chilean Species of Cycloneda Crotch (Coleoptera: Coccinellidae: Coccinellinae: Coccinellini)" (2008). USDA Systematic Entomology Laboratory. 44.

https://digitalcommons.unl.edu/systentomologyusda/44

This Article is brought to you for free and open access by the Entomology Collections, Miscellaneous at DigitalCommons@University of Nebraska - Lincoln. It has been accepted for inclusion in USDA Systematic Entomology Laboratory by an authorized administrator of DigitalCommons@University of Nebraska - Lincoln. 


\title{
A new Chilean species of Cycloneda Crotch (Coleoptera: Coccinellidae: Coccinellinae: Coccinellini)
}

\author{
NATALIA J. VANDENBERG ${ }^{1} \&$ GUILLERMO GONZÁLEZ ${ }^{2}$ \\ ${ }^{1}$ Systematic Entomology Lab, Plant Sciences Institute, Agriculture Research Service, USDA, clo National Museum of Natural History, \\ Smithsonian Institution, P.O. Box 37012, MRC-168, Washington, DC, E-mail: Natalia.Vandenberg@ars.usda.gov \\ ${ }^{2}$ Santiago, Chile, Nocedal 6455 La Reina, 56-02-4532998. E-mail: willogonzalez@yahoo.com
}

\begin{abstract}
Cycloneda pretiosa, new species is described from Lago Pirihueico in southern Chile The species is diagnosed and compared with both related and superficially similar species. Habitus and genitalic characters are illustrated. Geographical and temporal data are given. The new species is assigned to the Cycloneda germainii species complex and integrated into the key to species of this group (González and Vandenberg, 2006).
\end{abstract}

Key words: Insecta, Coleoptera, Coccinellidae, Cycloneda, new species, key, South America, Chile

\section{Introduction}

The tribe Coccinellini contains some of the more conspicuous and brightly colored members of the ladybird beetle family. While the group is well characterized in many regions, much of the diverse South American fauna has yet to be systematically collected and/or critically studied by specialists in the field. A recent review of the Cycloneda germainii species complex (González \& Vandenberg, 2006) uncovered three new species distributed in Chile and adjacent countries. Subsequently, examination of material from South and Austral Chile in the private collection of Alfredo Lüer has revealed the presence of yet another undocumented member.

The $C$. germainii species complex was erected as an informal grouping of species that possess similar dorsal color patterns and have often been confused with one another. The southern South American distribution and extremely similar male genitalia (e.g., parameres slightly shorter than basal lobe; basal lobe simple, predominantly planar, tapered distally with nipple-like or attenuate apex) suggest that the complex represents a natural grouping of closely related species (however we may have failed to recognize some immaculate species that should have been included). The above-mentioned characteristics are shared by the new species as well, although the vivid and highly contrasted dorsal color pattern insures that it will not be easily mistaken for other members of the group.

For a detailed historical review of Cycloneda see Vandenberg (2002).

\section{Material and methods}

The following institutional and private collections were consulted during this study or are depositories of type material for the new species (acronyms assigned here are used throughout the paper): 
The techniques employed by the two authors in the present study are described in González and Vandenberg (2006). Label data are given verbatim for the newly described species. Corrections or any supplemental interpretation of the label data is given in square brackets.

\section{Systematics}

\section{Cycloneda pretiosa Vandenberg \& González, new species}

(Figs.1, 2c, 3-8)

Diagnosis: Distinguished from other Cycloneda species by tarsal claw lacking a basal tooth (Fig. 2c), and distinctive tricolored elytron featuring a large sinuous black vitta and 3 or 4 yellowish cream-colored dots against a saturated red to orange background (Fig. 1). At present this is the only known species of Cycloneda where the tarsal claw is simply widened basally with a superficial medioventral notch (Fig. 2c), however two other members of the Cycloneda germainii species complex (C. lacrimosa González \& Vandenberg and C. disconsolata Vandenberg \& González) have a basal tooth that is greatly reduced in length (Fig. 2b).

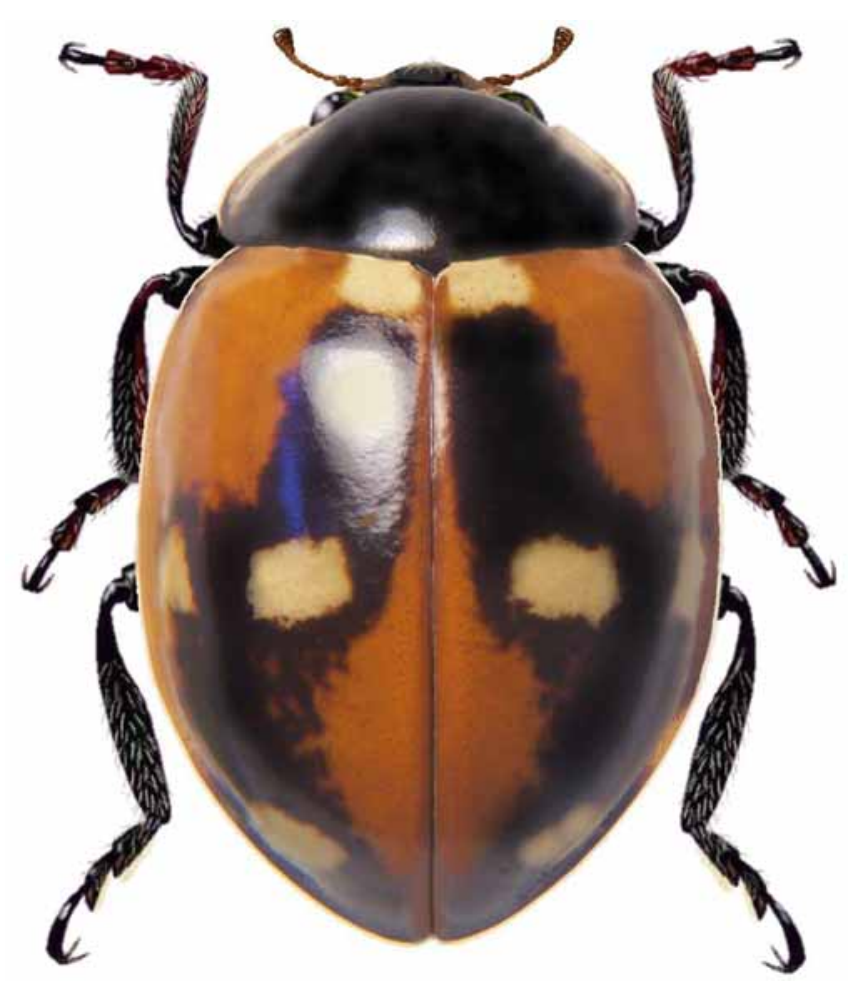

FIGURE 1. Habitus of Cycloneda pretiosa Vandenberg \& González, new species (female, paratype).

Although the one-two-one arrangement of yellowish cream-colored elytral maculae is consistent with other members of the $C$. germainii species complex, the appearance of the new species is perhaps more evocative of C. pulchella (Klug) from Brazil and Argentina and C. bioculata (Korschefsky) from Brazil, both tricolored species with a yellow to red background and round cream-colored spots embedded in larger black maculae. Upon closer examination, however, it is clear that the arrangement of the tricolored elements differs among these taxa, and both $C$. pulchella and $C$. bioculata are more orbicular in body form, with a much 
broader elytral epipleuron (subequal to width of frons) and different form of the male genitalia. Cycloneda pulchella has the basal lobe strongly, almost angularly curved down and then up, with a truncate apex and a dorsal patch of setae on each side near base, suggesting a closer affinity to $C$. emarginata (Mulsant) or $C$. ecuadorica (Timberlake), than to C. pretiosa. Cycloneda bioculata has a basal lobe that is much shorter and broadly rounded apically, with parameres that project well beyond the basal lobe.

Description (Holotype male): Length $3.5 \mathrm{~mm}$, width $2.3 \mathrm{~mm}$. Form elongated oblong, convex, apically pointed; elytral and pronotal margins narrowly reflexed. Punctation on dorsal surface fine, regular, with each puncture separated by $2-3 \mathrm{X}$ its diameter; surface between punctures shiny, with only faint trace of reticulation on head, not reticulate on pronotum or elytron.

Dorsal color pattern as follows: Head black with two irregular cream-colored spots, one at medial margin of each eye, extending from eye canthus to just below level of upper 1/3 of eye; eye black; labrum translucent brown. Pronotum (Fig. 4) black with triangulate yellow cream-colored spot beginning at anterior margin over medial margin of eye, tapered obliquely along lateral margin to basal $1 / 2$, enclosing entire anterior angle. Scutellum black. Elytral ground color reddish orange with black sinuous band, and four yellow cream-colored spots. Black band about $2 / 5$ elytral width, filling most of disc, beginning near suture just beyond scutellum at basal $1 / 8$, curved obliquely toward lateral margin just before basal $1 / 2$, then closely following elytral curvature, joined to lateral margin at apical $1 / 4$, continued along margin to apex. Four yellow cream-colored spots irregularly rounded to oblong, disposed as follows: first spot at base adjacent to scutellum, touching base of black band; second and third spots in a row slightly before middle of elytron, outer spot of pair adjacent to reflexed margin, inner spot midway between outer spot and suture; fourth spot oblong, situated in apical declivity at apical 1/5 adjacent to reflexed outer margin; first, second and forth spots forming oblique line, equally spaced. All margins of elytron with same orange of background color, except apex black. Lateral orange margins narrowly transparent.

Ground color of ventral surfaces black; elytral epipleuron orange, except apex black. Pronotal hypomeron straw-colored in apical 2/3; antenna, mouthparts brown; legs black, except tarsus obscure brown. Ventral surfaces including appendages clothed in decumbent silvery pubescence.

Eyes finely facetted separated by $2 \frac{1}{2} \mathrm{X}$ eye diameter; inner orbits nearly parallel in lower half, diverging at upper and extreme basal level. Antenna (Fig. 5) of 11 antennomeres, total length slightly greater than distance between eyes; third antennomere elongate, $1 \frac{1}{2} \mathrm{X}$ length of second, subequal to four plus five combined. Pronotum evenly convex except for very narrowly reflexed lateral margin; in outline with basal margin subsinuate, lateral margin strongly evenly arcuate, anterior margin subtrapezoidally emarginate; anterior angles subtriangulate, not conspicuous in dorsal view. Elytron elongate, in dorsal view with humeral angle rounded, weakly arcuate from beyond humeral angle to apical $1 / 3$, slightly sinuate at $2 / 5$ length, this more evident in ascendant side of elytron than in the reflexed margin; in lateral view (Fig. 3) unevenly arcuate, dorsally somewhat flattened in anterior $2 / 3$, more abruptly declivitous in posterior $1 / 3$, of approximately equal height at anterior, posterior $1 / 4$; epipleuron flat, horizontal in anterior $1 / 3$, progressively inwardly sloping in posterior half, with greatest width equal to about $1 / 2$ width of frons. Prosternum T-shaped, in ventral view with lateral arms gently folded back from stem, forming shallow arc in cross section; intercoxal process convex, inflated, apex truncate. Mesosternum trapezoidal; anterior border approximately linear with raised margin. Metasternum broad, with post mesocoxal line reaching lateral margin. Abdomen shortened semi-oval, broadest at second ventrite; postmetacoxal line of first abdominal ventrite curved posterolaterad, closely paralleling posterior margin for much of length, not attaining lateral margin; posterior margin of ventrites 1-5 linear; exposed portion of ventrite 6 rounded. Tarsal claw (Fig. 2c) without tooth, but with a superficial medioventral notch, wider in proximal $1 / 2$, evenly curved distally.

Male genitalia (Fig. 6a-c): Basal lobe elongate, roughly parallel-sided in basal 1/2, distal 1/2 tapered, apex attenuate; parameres slender, reaching 4/5 distance to apex of basal lobe; sipho (Fig.6c) curved, widened in last $1 / 3$; abruptly constricted, inflected in apical $1 / 6$. 

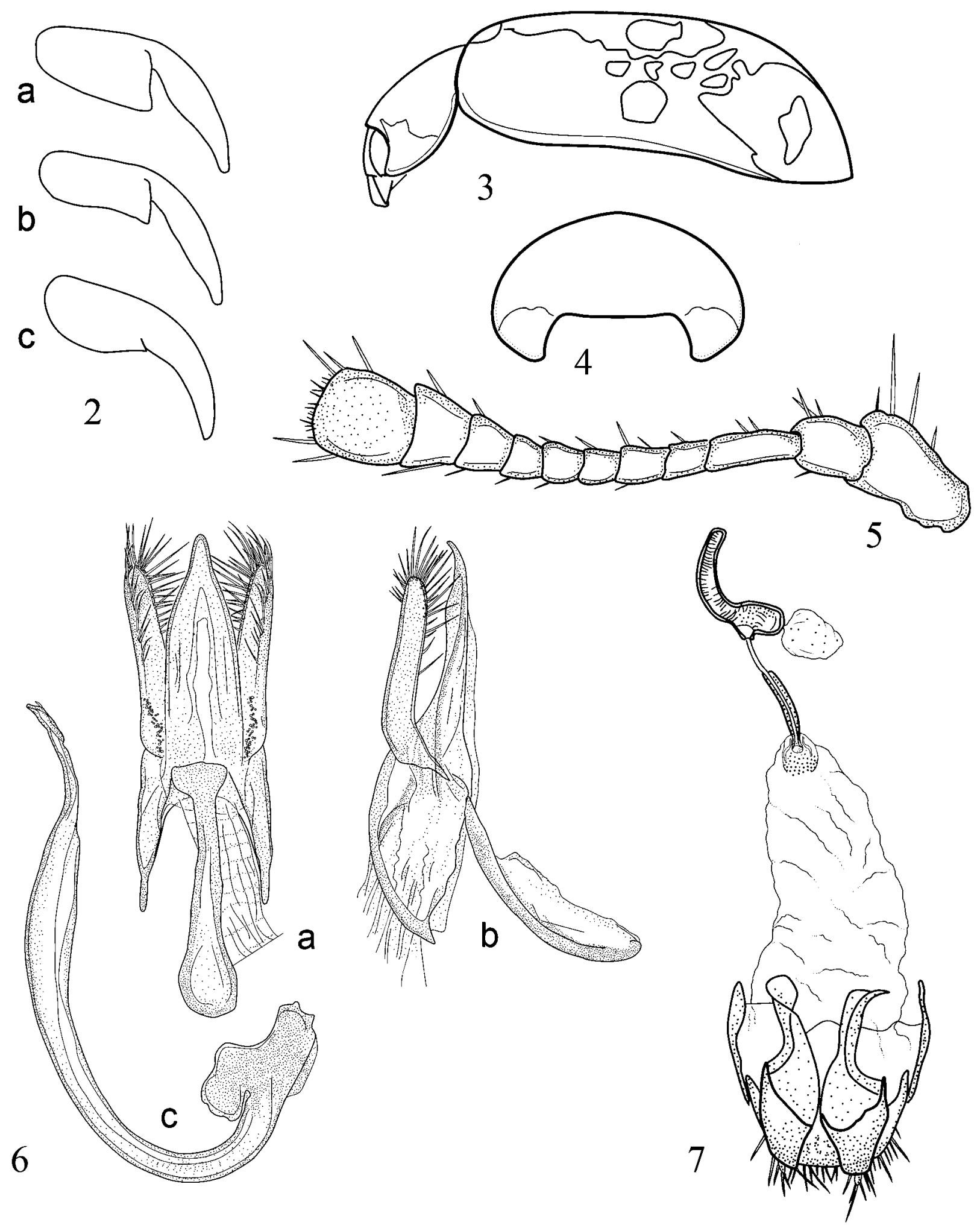

FIGURES 2-7. 2, Frontal views of left anterior tarsal claw, left half (a, with conventional length of tooth, Cycloneda eryngii (Mulsant); b, with short tooth, C. lacrimosa González \& Vandenberg; c, with obsolete tooth, C. pretiosa Vandenberg \& González, new species). 3, Left lateral view of $C$. pretiosa Vandenberg \& González, new species. 4, pronotal dorsofrontal view of $C$. pretiosa Vandenberg \& González, new species. 5, left antenna of C. pretiosa Vandenberg \& González, new species. 6, male genitalia of $C$. pretiosa Vandenberg \& González, new species (a, ventral view of phallobase; b, right lateral view of phallobase; c, right lateral view of sipho (=aedeagus)). 7, female genitalia of $C$. pretiosa Vandenberg \& González, new species, oriented with anterior end at top. 
Female: Similar to male, color slightly less reddish, black band narrower. The color pattern on the head as in the male, not gender specific. Female genitalia (Fig. 7) with spermathecal capsule weakly curved; infundibulum elongate, tubular.

Variation: Length 3.4 to $3.7 \mathrm{~mm}$. Fourth yellow cream-colored spot can disappear leaving only a fine yellow point. Black band can be expanded in lateral $2 / 3$, or can be partially dissolved, leaving a mackerel pattern.

Type material (map, Fig. 8): Holotype (male), "CHILE, Lo [Lago] Pirihueico [Comuna Panguipulli, Provincia Valdivia] fc [fecha] 15.01.02, coll: A.Lüer" (MNHN). Paratypes, Total 5 (females), 1 same data as holotype, 1 with date "18.01.02" and 3 with date "19.01.02" (2, MNHN; 1, USNM; 2, ALPC).

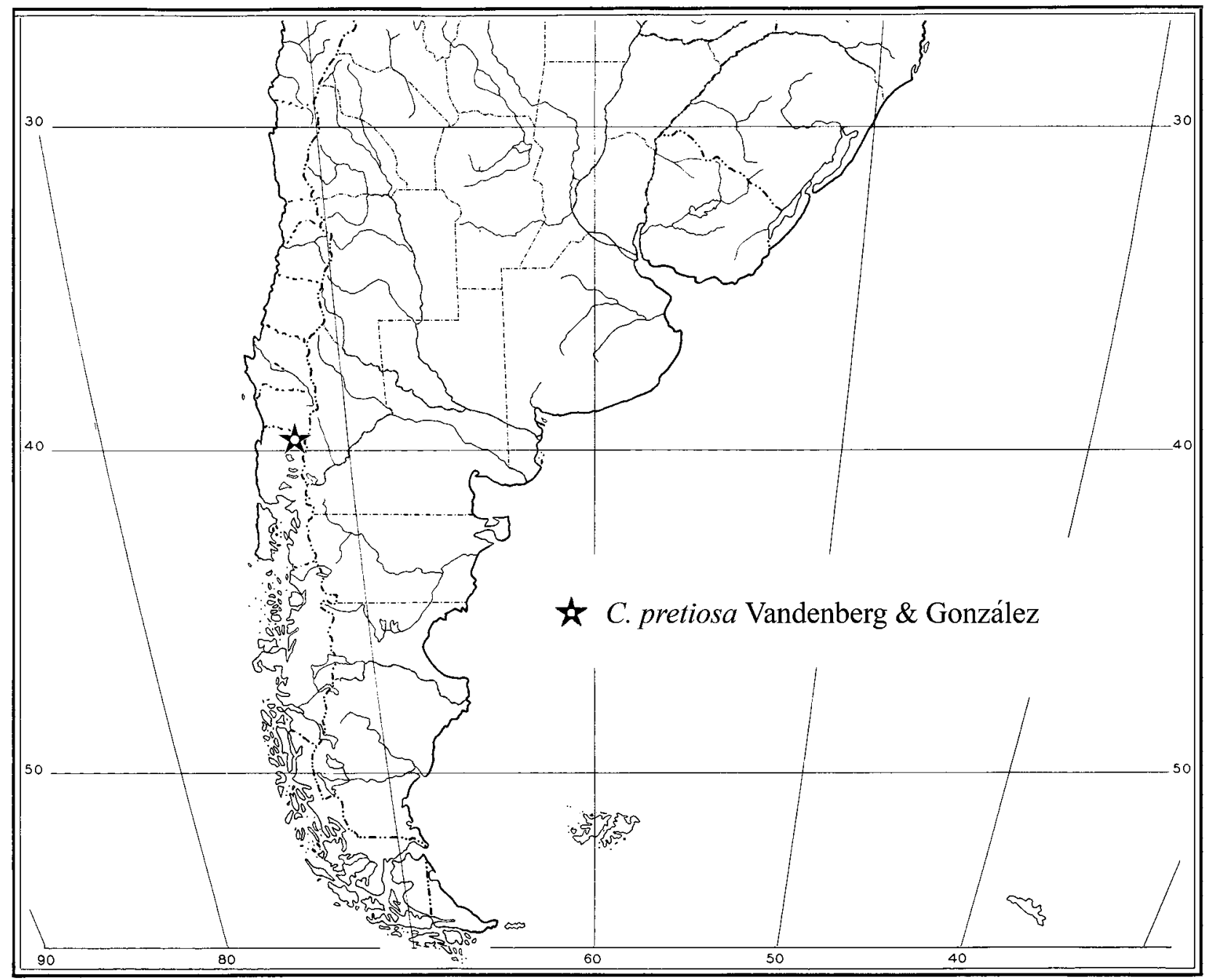

FIGURE 8. Distribution of Cycloneda pretiosa, Vandenberg \& González new species.

Etymology: From the Latin "pretiosa" meaning very beautiful and of great value.

Remarks: Cycloneda pretiosa can be incorporated into the existing key to species in the Cycloneda germainii species complex (González and Vandenberg, 2006) by adding an unnumbered couplet before existing couplet 1:

Tarsal claw simply widened at base, lacking tooth, but with superficial medioventral notch (Fig.2c); ground color of elytron saturated red or orange with contrasting markings in black and yellowish cream (Fig. 1); black mark beginning near elytral base and continued to apex, sinuous, not interrupted at midlength C. pretiosa Vandenberg \& González, n. sp. 
Tarsal claw with basal tooth (Figs. 2a-b); elytral color pattern not as above: ground color of elytron blackish, ferrugineus, or straw-colored; if orange then with a pair of irregular black marks generally well separated near midlength, or rarely with narrow connection at inner margins, and with cream colored markings absent or strongly suffused with orange ground color.... .1

\section{Acknowledgments}

We thank Alfredo Lüer for access to his unique private collection of southern and Austral Chilean Coccinellidae, and Michael Pogue, USDA-Systematic Entomology Lab (SEL), Washington, D.C. and Charlie Staines, Edgewater, MD for helpful suggestions on the manuscript. Lisa Roberts (SEL) reviewed and enhanced the drawings and did the layout for the plates.

\section{Literature cited}

González, G. \& Vandenberg, N.J. (2006) Review of lady beetles in the Cycloneda germainii species complex (Coleoptera: Coccinellidae: Coccinellinae: Coccinellini) with descriptions of new and unusual species from Chile and surrounding countries. Zootaxa, 1311, 13-50.

Vandenberg, N.J. (2002) The New World genus Cycloneda Crotch (Coleoptera: Coccinellidae: Coccinellini): Historical review, new diagnosis, new generic and specific synonyms, and an improved key to North American species. Proceedings of the Entomological Society of Washington, 104(1), 221-236. 